\title{
Margerete Brown
}

Im Juli 1934 fragte eine Margerete Brown aus Muskogee (Oklahoma) beim Malkin Conservatory in Boston wegen Unterrichts bei Schönberg an, wie durch einen Brief überliefert ist. Schönberg bietet ihr darin Einzelunterricht während seines Sommeraufenthaltes in Chautauqua an:

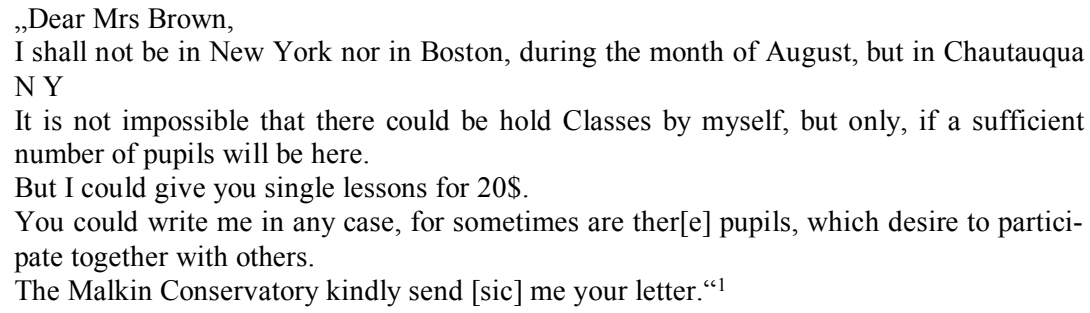

Ob Margerete Brown tatsächlich in Chautauqua im Sommer 1934 oder auch später Schönbergs Schülerin war, ist nicht eruierbar. ${ }^{2}$ Zudem ist fraglich, wer Margerete Brown überhaupt war: Das äußerst umfangreiche MusikerInnen-Verzeichnis MusicSack beispielsweise listet keine einzige „Margerete“, aber eine Komponistin mit dem Namen „Margaret Wise Brown“ (1910-1952), die jedoch als Kinderbuchautorin bekannt wurde. ${ }^{3}$ Die Schreibweise des Vornamens als Margerete ist unsicher, da diese nur durch Schönberg überliefert ist, wobei ihm möglicherweise ein ,verdeutschender' Schreibfehler unterlaufen ist.

1 Brief von Arnold Schönberg an Margerete Brown, 20. Juli 1934, Arnold Schönberg Center Wien, Briefdatenbank, ID 6665.

2 Sointu Scharenberg nennt in ihrer Studie zu Schönbergs Lehrtätigkeit ebenfalls keine Margerete Brown als Schülerin. Jedoch ist für das Jahr 1935 der Nachname „Brown“ angeführt; um wen es sich hier handelt, ist unklar. (Sointu Scharenberg, Überwinden der Prinzipien: Betrachtungen zu Arnold Schönbergs unkonventioneller Lehrtätigkeit zwischen 1898 und 1951, Saarbrücken: Pfau 2002, S. 331, 338.)

3 Siehe die Datenbank MusicSack, online verfügbar unter http://musicsack.com/PersonFMT Detail.cfm?PersonPK=100109520, aufgerufen am 6. September 2019. Eine Pianistin und Lehrerin mit dem Namen „Margaret Miller Brown“, die auch bei MusicSack angeführt wird, fällt in diesem Zusammenhang aus, da sie als Kanadierin registriert ist - Schönbergs Schreiben richtet sich jedoch an eine Adresse in Oklahoma. Siehe zu Margaret Wise Brown deren Homepage, http://margaretwisebrown.com, aufgerufen am 6. September 2019. 